\title{
The Regulatory Framework and Sustainable Development of China's Electricity Sector*
}

\author{
Yin-Fang Zhang ${ }^{\dagger}$
}

\begin{abstract}
Both supply- and demand-oriented solutions are important in cleaning up the electricity sector. However, their successful deployment calls for the removal of various barriers. This paper looks at China's electricity industry, one of the world's largest emitters of greenhouse gases, by relating the regulatory framework to the environmental dimension of sustainable electricity development. It develops an analytical framework by drawing upon the literature on the deployment of supply- and demand-side solutions, regulatory governance, and environmental policy integration. The paper finds that, in China's electricity sector, environmental considerations are subordinate to economic and development goals in policymaking and enforcement. Under the current regulatory framework, regulatory policies/instruments are not conducive to removing barriers to the effective deployment of the solutions.
\end{abstract}

Keywords: China; electricity sector; environmental issues; regulatory governance; environmental policy integration

China's dependence on dirty energy to fuel its economic growth for the last 30 years raises concerns about whether the economy can make a transition towards more sustainable development. Nowhere does such a transition pose a greater challenge than in the coal-dependent electricity sector, which is responsible for 40 per cent of China's $\mathrm{SO}_{2}$ and approximately half of its energy-related $\mathrm{CO}_{2}$ emissions. ${ }^{1}$ The key challenge is how to provide adequate power through an environmentally benign electricity sector.

Both supply- and demand-side solutions are crucial to achieving a "greener" electricity industry and involve the adoption of off-the-shelf technologies. However, owing to problems arising from the potential conflicts between

* The research on which this paper is based was funded by the British Academy Small Research Grant SG-54112. The views expressed are the author's and do not necessarily reflect those of the funding organization.

† University of Manchester. Email: Yin-fang.zhang@manchester.ac.uk.

1 Williams and Kahrl 2008. 
environmental and sectoral objectives, the promise of new technologies is insufficient to guarantee their successful deployment. ${ }^{2}$ Additional complexities may also arise in countries where the sector has undergone structural changes and regulatory reform, driven primarily by economic arguments. The body of empirical literature on the governance structure and process through which environmental concerns are addressed in the energy sector is growing, but it focuses mostly on developed countries. ${ }^{3}$ This paper attempts to fill the gap by developing an analytical framework useful for understanding the practices of less developed countries, and applying it to the case of China, one of the world's largest emitters of greenhouse gases. The last three decades have witnessed much reform in China's electricity industry. However, although the number of studies on electricity reform is growing, not many have related the regulatory framework to environmental concerns in the sector. ${ }^{4}$ This paper attempts to redress that omission. By applying the analytical framework, it examines the challenges arising from the regulatory framework to the deployment of supply- and demand-side solutions in China's electricity sector.

This paper continues by setting out the analytical framework. Then, after an overview of China's electricity industry, section four relates the regulatory framework to various barriers to the deployment of supply- and demand-side solutions. Challenges in the adoption of pollution-control measures are discussed in the fifth section, and the last section concludes.

\section{Analytical Framework}

In this section, I develop an analytical framework and use it as a basis from which to discuss the challenges for cleaning up China's electricity industry. The framework draws from the literature on the deployment of supply- and demand-side solutions, regulatory governance, and environmental policy integration.

\section{Barriers to the deployment of supply- and demand-side solutions}

Publications by energy organizations have emphasized the importance of deploying supply- and demand-side solutions in cleaning up the electricity sector. ${ }^{5}$ On the supply side, emissions from coal-fired generation can be reduced by closing down small generating units and replacing them with bigger, less polluting ones; using cleaner coal; or retrofitting coal-fired units with pollutant-capture equipment. ${ }^{6}$ Environmental gains can be obtained by switching from coal to less polluting fuels, preferably from renewable sources, in electricity generation.

3 For example, Collier 1997; Peterson and Rose 2006; Knudsen 2010.

4 Williams and Kahrl 2008; Kahrl et al. 2011; and Lema and Ruby 2007 are among the few studies that relate electricity reform to environmental issues. Analysis of institutions and sustainable energy development is also included in Garcia 2013 and Andrews-Speed 2010, 2012.

5 Such organizations include the World Energy Council, IEA, World Bank, etc.

6 IEA 1999. 
In addition, pollution can be reduced by improving generation efficiency, as a given energy output could be produced by using less fuel. ${ }^{7}$ Solutions on the demand side usually come under the name of demand-side management (DSM), which aims to contain electricity demand through "a structured means of promoting end-user energy efficiency (EE) and energy savings."

However, various barriers may prevent the full realization of the potential gains from these solutions. Economic barriers relate to market distortions or market failure caused by high costs and externalities associated with the solutions. Replacing small coal-fired units with bigger ones, fitting pollutant-capture equipment and installing renewable capacity all require substantial upfront investment and the continuous injection of capital to cover operating costs, thus making such solutions less cost-competitive. However, cleaner plants carry positive externalities - less pollution. The cost disadvantages compared with the environmental benefits of the solutions represent a potential market failure, and so policies are necessary in order to create a level playing field for plants using different technologies. But, why do the environmental benefits lead to market failure? Apart from financial support, appropriate investment planning methodologies and licensing rules, price regulation, and dispatch arrangements are all essential to overcome the economic barriers.

Both investment planning methodologies and project approval rules affect the types of plant that are constructed. To lend support to cleaner plants/technologies, it is important for environmental costs and benefits to be integrated into the planning process for investment in generation capacity, and for environmental standards to be considered as one of the main criteria used in project approval. ${ }^{9}$ On-grid electricity tariffs need to be set at a level to allow for the recovery of investment costs and to give recompense for the environmental benefits of cleaner plants and/or technologies. Price adjustment mechanisms such as emission charges can also be used as a cost adder to internalize pollution damage not fully reflected in electricity prices. ${ }^{10}$ Appropriate pricing (probably together with the charging of emission fees) can increase the attractiveness of using cleaner plants to generate and dispatch power. This may be particularly important in an unbundled electricity industry where profit-driven power producers would otherwise make dispatch decisions based purely on the principle of cost efficiency: plants with low operating costs (but which tend to be dirtier) will be used more than those with high operating costs. To promote the development of renewables, price-based schemes are usually combined with quantity-based measures such as renewable portfolio standards, along with arrangements that ensure grid access and institute purchase obligations. ${ }^{11}$

7 The technical definition of energy efficiency on the supply side is thermal efficiency. The term "generation efficiency" is used here to cover both thermal and non-thermal plants.

8 IEA 2006, 107.

9 IEA 2006.

10 Green 2008. Emission charges are also called pollution taxes or levies.

11 World Bank 2008. 
To improve generation efficiency, it is crucial that there are provisions in on-grid tariffs which incentivize power producers to adopt efficiency-enhancing practices. ${ }^{12}$ Competition may also come into play by compelling incumbents to use inputs more efficiently.

On the demand side, bringing end-user electricity prices closer to the actual level of costs would give consumers the incentive to save energy and improve EE. ${ }^{13}$ However, EE technologies often require high upfront capital and additional costs, while savings accrue over time and carry positive externalities. ${ }^{14}$ To overcome the economic barrier associated with the public goods nature of EE technologies, the international practice is to direct EE incentives to households and firms through DSM programmes that are usually provided by grid companies. ${ }^{15}$ To do so, there should be incentives for grid companies to invest in DSM programmes, usually through appropriate price regulation which allows for the recovery of costs. ${ }^{16}$

Although pivotal for the effective deployment of demand- and supply-side solutions, the removal of economic barriers may require the elimination of non-economic obstacles, ${ }^{17}$ which I categorize into institutional and structural barriers. ${ }^{18}$ Structural barriers relate to the features of the industrial and corporate structure. In the generation sub-sector of an unbundled electricity industry, the dominance of the incumbents in plant development and generation can be seen as a structural barrier in that it may deter the entry of other players. ${ }^{19}$ Policies to tackle this usually aim at breaking up this dominance and permitting independent power producers (IPPs). Such policies bring at least two potential environmental gains. First, they place incumbents under competitive pressure to improve generation efficiency. Second, they help to promote the development of renewables because, according to international organizations such as the World Bank, IPPs tend to be the main developers of renewable energy projects.

Another structural barrier in an unbundled electricity system is related to grid access. To encourage the development of renewables and IPPs, it is necessary to reduce the amount of discretion grid companies have over grid access by bringing them under the authority of the sector regulator. ${ }^{20}$ Subjecting them to regulatory

12 For a review of the theories and practices of incentive regulation, see Hemphill, Meitzen and Schoech 2003.

13 In practice, it may prove sensitive and difficult to raise end-user prices, in particular for residential users, because of the issues of accessibility and universal service. Such social objectives will be discussed later in the paper.

14 World Bank 2008.

15 Ibid.

16 IEA 2006.

17 Garcia 2013.

18 Note that technology has an important role to play in cleaning up the sector. However, I do not address the technological barriers separately here; rather, they are integrated into, where necessary, the discussion of economic, structural and institutional barriers. The categorization of the barriers is conceptual. In the real world, the differences between them are not always clear-cut and policies to overcome them are often intertwined.

19 Global World Energy Council 2005.

20 World Bank 2008. 
authority is also important for demand-side solutions in that it is a prerequisite for imposing incentive-based regulation and mandatory requirements for companies to invest in DSM programmes.

Institutional barriers refer to some features of the institutional structure which may hinder the deployment of effective solutions. The literature has emphasized that it is essential to improve institutions in order to overcome structural and economic barriers. ${ }^{21}$ It is important to have in place the institutional arrangements by which transparent and clear price structures that reflect costs (including those associated with externalities) are set and enforced; investment projects are approved according to well-defined procedures in which environmental concerns are incorporated; and incumbents (particularly grid companies) are effectively regulated. Because tackling environmental issues in the sector involves diverse policy arenas, coordination mechanisms are needed for joint policymaking and priority setting among various agencies. ${ }^{22}$

The policy prescriptions discussed above are largely normative. Practices adopted in the real world, in particular in developing and transitional economies (like China), will unsurprisingly deviate from the guidelines. To bring in positive elements that help to explain real-world practices as they occur, my analytical framework draws on the literature on regulatory governance and environmental policy integration.

\section{Regulatory governance: an institutional perspective}

The institutional perspective of regulation places emphasis on the institutional determinants of regulatory policy. Levy and Spiller have distinguished between regulatory governance and regulatory incentives. ${ }^{23}$ Regulatory governance involves "the mechanisms that societies use to constrain regulatory discretion and to resolve conflicts that arise in relation to these constraints." 24 Regulatory incentives are the effective rules derived from regulatory policies/instruments regarding pricing, subsidies, entry, interconnection, etc.

In general, a primary function of regulation in public utilities such as electricity is to address issues arising from the specific features of the industries - large sunk investments, economies of scale, and the mass consumption of products/services. Regulation seeks to allocate costs across producers and consumers in a way that maintains investors' willingness to invest while minimizing the cost of service provisions. ${ }^{25}$ It also seeks to achieve sectoral social objectives, such as universal service which emphasizes access to the product at affordable prices, an issue more pronounced in developing countries. Regulatory outcomes - in other words, how well the sectoral objectives are served - depend on the incentives formed

21 For example, IEA 2008; Garcia 2013.

22 IEA 2007, 2008.

23 Levy and Spiller 1994.

24 Ibid., 205

25 Bonbright 1961; Littlechild 1983. 
by regulatory policies/instruments, which are in turn determined by the governance structure and process of rule-making and enforcement and their link to the underpinning institutional environment. ${ }^{26}$ In regulated industries, various actors, including governments, regulatory agencies, and regulated firms, relate to one another within a broad institutional framework. ${ }^{27}$ Regulatory regimes differ in the degree to which regulatory agencies are related to the government and other agencies, and how close regulatees are situated in the structure. ${ }^{28}$ By analysing the institutional determinants of regulation, attention is paid not only to the formal attributes of the actors and their relations, but also to the informal distribution of power among them. ${ }^{29}$ In other words, regulation can be analysed as the outcome of complex exchanges between the actors. ${ }^{30}$

The literature on regulation and regulatory governance in public utilities is concerned mainly with the regulatory design through which sectoral objectives are addressed. However, there is another market failure in the electricity sector - environmental externalities - which also calls for regulatory intervention. Although environmental issues are traditionally addressed by environmental policy, there is a recognition that the environmental sector alone cannot secure environmental objectives and that non-environmental policy areas need to consider environmental effects. ${ }^{31}$

\section{Environmental policy integration}

Integration of environmental concerns into other policy areas is referred to as environmental policy integration (EPI). There is no agreement on its definition or on how much weight environmental objectives should receive. A "strong" definition assigns principle priority to environmental considerations, ${ }^{32}$ while a less "strong" view emphasizes the removal of contradictions between policies and a balanced approach towards environmental and energy-centred objectives. ${ }^{33}$ Further down the spectrum is "weak" EPI, which argues for simply considering environmental concerns when formulating and enforcing policies in other sectors. $^{34}$

EPI is seen as not just a state of affairs, which is the aim of policymaking, but also as the process necessary to achieve change. ${ }^{35}$ Two factors are important for understanding the process and outcomes of policy integration: functional overlap

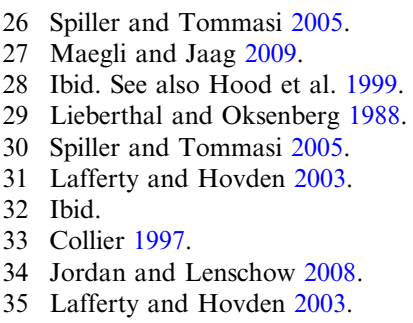


between environmental and other goals - whether they are synergistic or conflictive; and political commitment to environmental objectives. Together, these factors determine the position of environmental considerations in relation to sectoral and other objectives in policymaking and enforcement. Seeing EPI as a process is to take an institutional perspective and place emphasis on the institutional and policy contexts. This means focusing the analysis on the governing structure and process that take place inside political systems in which different actors interact and employ different combinations of policy instruments. ${ }^{36}$

\section{Towards an analytical framework}

The analytical framework used in this paper is developed by combining the three blocks of literature discussed above. Guidelines issued by international energy organizations on how to overcome the barriers describe the desirable attributes of policies and institutions, but are largely normative. To understand actual practices adopted, the institutional perspective of regulation is brought in, which links policy outcomes with the institutional determinants of regulatory policy/instruments, thereby bringing regulatory governance into the discussion and highlighting its role in determining regulatory incentives. The literature on EPI is drawn upon to extend the analysis of regulatory governance to the governance structure and process through which environmental considerations are (or are not) integrated into sectoral policies. The policy outcome depends on whether the removal of the related barriers can be facilitated by regulatory incentives arising from the policies/instruments thus made and enforced in the sector.

When examining the outcome of integrating environmental and sectoral policies, it is useful to analyse functional overlap among various objectives and the political commitment to environmental considerations. The electricity sector is associated with multiple goals, including environmental and sectoral economic and social objectives. In addition, the industry carries development goals because of its key role in promoting economic growth in a country like China. ${ }^{37}$ Given the mass consumption of electricity and the universal-service obligation, governments may intervene in the sector to win political support. ${ }^{38}$ Note that what is referred to as governments includes both central and sub-national governments, as the latter play an important role in policymaking and enforcement in a country like China. Therefore, it is necessary to incorporate the misalignment of interests and priorities between governments at different levels into the analysis. As has been said, the extent to which different objectives are functionally synergistic or conflictive, together with governments' commitment to environmental considerations, decides the priority order of various objectives in the policy process and affects the power distribution among various actors and the ways in which 
they interact with one another. It is where institutional barriers may arise, which may then result in the features of industrial and corporate structures that stand as structural barriers. Together, they will impact on what regulatory policies/instruments are adopted and how they are implemented in the sector. Whether the deployment of supply- and demand-side solutions will be facilitated depends on the extent to which the incentives from the policies/instruments and their enforcement are conducive to overcoming related economic barriers.

The following sections apply the analytical framework to China's electricity sector by analysing data collected from various sources. Second-hand data were collected from the websites and publications of regulatory agencies and government departments; reports in newspapers and magazines; the publications of international organizations and the academic literature on China's electricity industry. They were supplemented by data collected through individual interviews with officials at regulatory agencies and government departments, and researchers who have conducted extensive research in related areas (see Appendix for details). Data triangulation was used to provide cross-validity and to help reduce potential bias in individual data sources and informants. Based on information cross-checked among data sources, the regulatory framework is applied to the deployment of supply- and demand-side solutions in China.

\section{Overview of China's Electricity Sector}

Before 1997, China's electricity sector was vertically integrated and headed by the industry ministry. To combat severe power shortages, a policy was implemented in 1985 which granted provincial governments the authority to approve investment projects with a capacity of 50MW or below, and opened electricity generation to private investors. Consequently, local, small-scale power plants proliferated. ${ }^{39}$

In 1997, the industry ministry was dissolved and the State Power Corporation (SPC) was established to oversee the business operations of the sector while the ministry's policymaking functions were transferred to the now-called National Development and Reform Commission (NDRC). In 2002, the SPC was unbundled into five national state-owned generating companies (the Big Five hereafter) and two grid companies. The Big Five, which controlled about half of China's total generation capacity, were expected to compete with one another and with other power producers. ${ }^{40}$ The two grid companies owned over 90 per cent of the total transmission and distribution assets.

In 2003, the State Electricity Regulatory Commission (SERC) was established as the sector regulator and was mandated with wide-ranging statutory powers. However, the NDRC, the de facto chief regulator of the sector, still took the

40 State Electricity Regulatory Council 2011. 
lead in two important policy areas - pricing and investment project approval. The price bureau of the NDRC and its local offices set electricity tariffs, and the NDRC's energy bureau and its provincial branches issued investment permits. In 2008, the energy bureau was reformed into the National Energy Administration (NEA), but remained under the jurisdiction of the NDRC. ${ }^{41}$ The SERC was folded into the NEA in early 2013, with a proposal to completely dissolve the sector regulator. This change consolidated NDRC's authoritative grip over the power sector.

Other agencies involved in the regulatory structure include the State-owned Asset Supervision and Administration Commission (SASAC), which is responsible for managing the assets in state-owned electricity companies, and the Ministry of Environmental Protection (MEP), which is responsible for environmental issues in the sector. ${ }^{42}$

\section{Regulatory Framework of China's Electricity Sector and Barriers to Supply- and Demand-side Solutions}

The analysis in this section draws mostly on the situation prior to the SERC being absorbed into the NEA; however, the argument based on the analytical framework can be readily extended to any changes thereafter. As the reduction of economic barriers first requires the removal of non-economic ones, the section begins with an examination of the extent to which the regulatory framework serves as an institutional barrier, and then moves on to structural and economic barriers.

\section{Institutional barriers}

Owing to its strategic importance, the electricity sector has been tightly controlled by the Chinese government. ${ }^{43}$ It has been a political base for China's bureaucracies, with many Party and government leaders having roots in the industry. ${ }^{44}$ This connection has ensured the sector's prime position in centrally made policies and, conversely, has made it easier for the government to maintain control over the industry. After the industry ministry was dissolved in 1997, authority for making sectoral policies remained with state commissions. This situation has not fundamentally changed, even with the establishment of the SERC, because the NDRC has maintained control over what really matters in the sector - pricing and investment approval. As the key bureaucratic arm of the Chinese Communist Party, the NDRC is responsible for formulating and implementing strategies for national economic development and for putting forward polices of macroeconomic

41 For consistency, the energy bureau is referred to throughout the paper when discussing project approval.

42 The MEP was formed in 2008 from the former State Environmental Protection Administration.

43 Hsueh 2011.

44 See Chen 2010 for a discussion of the ties between the sector and top government leaders. 
management. ${ }^{45}$ Electricity policies formed by the NDRC are integral parts of the national economic development plans, and ensuring an adequate electricity supply is their primary guideline. ${ }^{46}$ Policies on end-user electricity prices formulated by the NDRC's price bureau serve the commission's function of overseeing general price stability and managing inflation. ${ }^{47}$ It should be noted that such electricity policies may ultimately be intended to maintain political legitimacy, as inadequate energy supply and social instability are considered as serious threats to the economic interests of the country and therefore to the survival of the party-state. ${ }^{48}$

As the sector regulator, the SERC has a nominal mandate to oversee competition and prevent market domination in electricity generation. In addition, it mediates and adjudicates disputes between power plants and grid companies over grid connection and access. However, its status has not been supported by law and, having no say in investment approval and electricity tariffs, it lacks the necessary regulatory power to deliver on its mandates. ${ }^{49}$ Despite being called an "independent" regulator, its independence is questionable because of its industrial and political ties. When abolished in 1997, the industry ministry transferred its staff to the SPC (which was later unbundled into the Big Five and the grid companies), NDRC's energy bureau, and later to the SERC. Personnel continue to move between these organizations. ${ }^{50}$

The MEP is supposed to play an important and primary role with regard to environmental issues. It is responsible for national environmental governance and participates in the formulation of plans associated with trans-boundary environmental problems. ${ }^{51}$ According to the Environmental Protection Law, effective from 1989, environmental protection facilities must be concurrently designed, constructed and operated with all new power plant projects. The MEP has authority to withhold endorsement of any projects that fail to satisfy these requirements, and can suspend any project in the course of construction if it fails to comply with the law. However, the NDRC can approve power projects that do not meet environmental standards in the case of power shortages. ${ }^{52}$

Each of these different agencies has been competing for rule ownership and policy formulation, with the NDRC appearing dominant in the game. ${ }^{53}$ Nevertheless, there lacks coordination among different policy areas. According to the Supervision and Administration of the Power Industry Directive, enacted in 2005, the SERC is mandated to cooperate with the MEP to supervise the

45 http://en.ndrc.gov.cn/mfndrc/default.htm.

46 Interview with central-level officials, Beijing, November 2010

47 http://en.ndrc.gov.cn/mfndrc/default.htm.

48 Andrews-Speed 2010.

49 Qiu and $\mathrm{Li} 2012$.

50 Cheng and Tsai 2009. One of the NDRC officials interviewed in Beijing in January 2011 had previously served in one of the Big Five.

51 Chang and Wang 2010.

52 Cheng and Tsai 2009.

53 Lema and Ruby 2007; Lin and Purra 2010. 
implementation of environmental regulations and standards in the sector. However, with no authority over pricing and investment approval, the SERC has no means to accomplish the coordination. ${ }^{54}$

Another feature of the regulatory framework relates to the traditional quasifederalist structure of government administration in China, the significant degree of decentralization in policymaking and enforcement. To protect local interests and promote local development, governments at sub-national levels may ignore, bypass or not fully enforce rules issued by the central government. ${ }^{55}$

In the electricity sector, the delegation of decision making to the provincial level in the mid-1980s has unwittingly increased local control over the electricity system. Divergence in interests between the central and local governments has led to the emergence of parallel policy agendas, with the most striking jurisdictional conflict lying in rate making and investment planning. ${ }^{56}$ Final local tariffs for both power generation and consumption are decided by local price offices, which are subject to the scrutiny of the NDRC's price bureau. To promote local development and driven by self-reliance, provincial governments have used their discretionary powers to approve a large number of small-scale power projects. Applications for larger projects are submitted to the NDRC through its provincial branches. Although powerful, the NDRC at the central level is understaffed. ${ }^{57}$ Limited capacity, together with information asymmetry, makes it difficult for the state commission to investigate all proposed projects thoroughly and review prices submitted by its local units. ${ }^{58}$

In fact, central agencies often have just a modicum of authority over their local offices, even though the latter are formally part of the former's vertical chain of command. ${ }^{59}$ Provincial branches of the SERC rely on local labour markets for staffing and local governments for information. Provincial offices of the NDRC and MEP are financed by, and required to report to, provincial governments. ${ }^{60}$ Collusion is pervasive among local governments, local state-owned electricity companies and local branches of central agencies, making it easy to advance local interests but potentially difficult to enforce national policies. ${ }^{61}$ Appraised according to their economic growth, local governments tend to deprioritize compliance with environmental targets and related policy initiatives set by the central government.

54 Interview, central-level officials.

$55 \mathrm{Xu} 2011$.

56 Williams and Kahrl 2008.

57 Cheng and Tsai 2009; interview with NDRC officials, Beijing, January 2011.

58 Sun, Guo and Zheng 2012.

59 Lieberthal and Oksenberg 1988.

60 Cheng and Tsai 2009.

61 Andrews-Speed 2010. 


\section{Structural barriers}

The grid companies and the Big Five have political connections through the membership of their key executives in the Central Committee of the Chinese Communist Party and because of the sector's importance as a political base for government leaders. ${ }^{62}$ They also have ties with the NDRC and SERC through the "old-boy networks" of ex-industry ministry staff. Therefore, the companies have become too powerful to be fully subject to the authority of the agencies. Their dominance is particularly obvious when up against the SERC, given the latter's precarious institutional standing and the fact that the top managers of the companies hold administrative ranks on a par with the SERC's chairman. ${ }^{63}$

To promote competition in electricity generation, the SERC issued a 20 per cent cap on the market share of any single firm in any single region. However, evidence shows that the Big Five did not strictly abide by this. For instance, China Power Investment Corporation (one of the Big Five) has a market share of more than 20 per cent in both the north-eastern and north-western markets. ${ }^{64}$ The reason, to a great extent, relates to fragmented authority and conflicting agendas among the governing agencies. The SASAC has actively promoted the expansion of the Big Five in all segments of the electricity generation sub-sector. Facing rising coal prices, the companies integrated upwards to run their own coalmines, encouraged and endorsed by the SASAC and NDRC. ${ }^{65}$ They have gained the franchise for developing all of China's major rivers, leaving no room for private participation in large-scale hydropower stations. ${ }^{66}$ Three of them are leading players in other renewables. ${ }^{67}$ Despite its mandated responsibility for ensuring competition in electricity generation, the SERC is unable to stop the expansion of these companies. ${ }^{68}$ Consequently, the Big Five's dominance has even increased slightly, with their share in installed capacity rising from around 40 per cent at the time of unbundling in 2002 to 49 per cent in $2010 .{ }^{69}$

The upward integration and continued dominance of the Big Five serve as effective barriers to the sector for IPPs, despite the fact that the legal barriers to entry were removed as long ago as the mid-1980s. ${ }^{70}$ Constrained by access to finance, IPPs tend to develop small-scale power projects, the approval of which rests with provincial governments. However, at the local level, state-owned projects often enjoy preferential treatment in investment approval, whereas private investors may be disadvantaged if they lack local connections. ${ }^{71}$

62 Chen 2010.

63 Lin and Purra 2010.

64 Sun, Guo and Zheng 2012.

65 Zhang, Yanhua, and Chen 2011.

66 Sun, Guo and Zheng 2012.

67 Ibid.

68 Zhang, Yanhua, and Chen 2011; interview, central-level officials.

69 State Electricity Regulatory Council 2011. The figures referred to were based on the installed capacity owned by the five companies, excluding those controlled by their listed subsidiaries which are substantially independent and therefore counted as IPPs.

70 Garcia 2013.

71 Sun, Guo and Zheng 2012 
Consequently, there has been a general withdrawal of private investment along with a proliferation of small-scale, local-based power plants. ${ }^{72}$

The grid companies are regional monopolies. In the presence of a natural monopoly, access regulation is important to ensure power producers have equal access to the transmission wires - exactly what the SERC is mandated to do. However, given the SERC's weak authority, the grid companies have significant discretion over grid access. ${ }^{73}$ They favour their affiliated generating plants and other state-owned power stations over privately invested power producers. ${ }^{74}$ In addition, the grid companies favour coal-fired electricity over renewables because they are unable to pass on to consumers the losses they face when purchasing renewable energy (this issue is discussed in detail below). Their dominance over the sector also means that it is potentially difficult for the SERC to mandate these companies to invest in DSM programmes (discussed below).

\section{Economic barriers}

Overcoming economic barriers on the supply side involves creating conditions that level the playing field for plants of varying degrees of "greenness," with pricing, investment planning and dispatch arrangements all playing an important role. Moreover, pricing is important for demand-side solutions because it provides incentives for end-users to save energy and for grid companies to invest in DSM programmes. In China, there are two sets of electricity prices: on-grid tariffs - the wholesale prices paid by grid companies to power stations; and catalogue prices - the prices paid by end users to grid companies. The NDRC and local price offices set both prices.

As the economic planning body, the NDRC sets on-grid tariffs that should allow for capacity expansion to keep up with China's fast economic growth. ${ }^{75}$ A model of "cost repayment plus return" has been adopted to serve this purpose. Both prices and volume quotas are set in power purchase contracts to allow for the recovery of investment costs and the earning of reasonable profits. Under a quota-based dispatch system, annual operating hours are allocated to power stations according to their capacity size. ${ }^{76}$ The NDRC issues a guidance price for each region and then allows local price offices to make adjustments and decide the final prices for individual power producers. ${ }^{77}$ Owing to the collusion between

72 In China, "IPP" is used as a broad term to cover local government-invested generating companies, listed subsidiaries of the Big Five, and private-invested power producers. The barriers discussed here relate mainly to private IPPs.

73 The State Grid Corporation covers 22 provinces in northern and western China and the South Power Grid manages transmission networks in five southern provinces. Tensions and conflicts exist between the major grid companies and their provincial subsidiaries (see Williams and Kahrl 2008 for a detailed discussion). Nonetheless, no distinction is made between them here because they both discriminate against privately-owned power stations and renewables.

74 Zhang, Chi, and Heller 2004.

75 Kahrl et al 2011.

76 Pilot projects for "energy efficient dispatch" were implemented in selected provinces in 2007. Nationwide implementation was planned but postponed. See Kahrl, Williams and Hu 2013.

77 Ma 2011. 
local governments and local price offices, local tariffs tend to be higher than regional guidance prices, and the tariffs received by well-connected power producers - mostly local state-owned companies - are usually more favourable than those for private IPPs. ${ }^{78}$

The same pricing model and process are used for renewables, except for large national projects granted through a bidding-based concession scheme (discussed below). Recently, feed-in tariffs (FITs) have been introduced to make the installation of renewable capacity more attractive by adding a premium to the average wholesale prices of coal-fired electricity. ${ }^{79}$ Nonetheless, the price difference between coal-based power and renewables does not compensate for the positive externalities of the latter. ${ }^{80}$

Efforts have been made to introduce emission charges. However, these efforts have encountered difficulties owing to the conflicts arising between governing agencies. Five agencies are involved, namely the SERC, NDRC, MEP, the Ministry of Finance, and the State Tax Administration. The conflicts revolve around the charge bands, how to track emissions, who should bear the cost of installing the tracking system, who should collect the levies, and how the revenues raised should be used. ${ }^{81}$ Furthermore, the implementation of emission charges has met with local resistance because of the divergence in priorities between central and provincial governments. ${ }^{82}$ These problems impede the creation of a level playing field for different generating technologies and, under the current dispatch system, discourage power generation and dispatch from cleaner plants as they fail to improve the cost-competitiveness of "greener" generating units against dirtier ones.

The way in which on-grid tariffs are set provides little incentive for power producers to improve generation efficiency because there is no provision for tariff reduction over time. The involvement of local governments in setting local tariffs shields local power producers from pressure to adopt efficiency-enhancing practices. Various entry barriers for IPPs and the dominance of the Big Five at the national level and local state-owned power producers at the provincial level mean that there is little pressure from competition to improve generation efficiency.

The NDRC issues guidance on end-user prices and the final rates are decided by local price offices. Overall, prices are set to achieve political and social objectives and according to the types of user, namely industrial, commercial, residential and agricultural. In accordance with the desire to promote economic growth, electricity prices for industries have been kept low, and thus there is little incentive for industrial firms to improve energy efficiency and adopt EE technologies.

78 Sun, Guo and Zheng 2012.

79 The premium varies according to energy technologies, geographic locations and availability of renewable resources.

80 Liao et al. 2010; Garcia 2013.

81 Zhang, Zhe, and Xi 2010; interview, central-level officials.

82 Williams and Kahrl 2008. 
In order to maintain social stability and contain inflation, residential electricity prices are set far below costs and according to affordability. Such a price scheme may be conducive to meeting the universal-service obligation, but it does not encourage rational electricity consumption or the adoption of energy-saving appliances.

There is no separate price for the use of the grid network, and the revenues of grid companies depend on the discrepancy between on-grid and end-user prices. Owing to difficulties in approving increases in end-user prices, the price premium for renewables squeezes grid companies' revenues, making them resistant to any increase in FITs that would increase the market competitiveness of renewables. These companies have been unwilling to connect and buy electricity from renewable power plants, even though they are obliged to do so under the power purchase agreements. ${ }^{83}$ There is also little incentive for them to invest in DSM programmes because the costs cannot be recovered through their revenues.

\section{Further discussion}

It's clear from the discussion above that electricity pricing and dispatch arrangements have been driven primarily by the need for a rapid expansion of capacity, and little consideration has been given for environmental issues. Investment planning has been guided by the overriding principle of ensuring adequate electricity at the central level, and leans towards the promotion of local interests at the provincial level. There is no incentive for grid companies to purchase renewable energy. The way in which end-user rates are set provides little encouragement to save electricity and improve EE. These policy outcomes can be better understood by applying the analytical framework, which emphasizes the institutional determinants of regulation/policy and the factors which determine the position of environmental considerations in relation to other objectives in policymaking and enforcement.

China's electricity sector serves various objectives. There are the sectoral economic objectives to maintain and expand the provision of services, and sectoral social objectives which relate to universal service. Environmental protection is becoming an increasingly important objective. The sector also carries diverse development goals, the most important of which is to increase the power supply to fuel current and future economic growth. ${ }^{84}$ The government has intervened in the sector for political objectives - preserving political legitimacy and the rule of the party-state - by pursuing the development goals and maintaining social stability. ${ }^{85}$ However, there is another political dimension which relates to the party-state maintaining control over the economy through keeping a firm hold 
on this strategically important industry. ${ }^{86}$ With regard to the development and political objectives, it is also necessary to bring into the analysis the complex relations between central and local governments. While the central government puts emphasis on the role of the sector in overall economic planning and macroeconomic management, local governments are more interested in developing local industries, maintaining employment and promoting other local interests.

There is considerable and complex functional overlap among the various objectives. The central government's ultimate objective is to maintain political legitimacy. This overlaps in a highly synergistic way with sectoral economic objectives and development goals, in that the economic policy of the sector serves the development goals and economic development deemed necessary for political legitimacy. Stressing accessibility and affordability, the universal service obligation is functionally in line with the government's social-related development goals, which in turn serve the political objective of maintaining social stability. As state ownership has traditionally been used as a means of maintaining economic control, preservation of the party-state's control over the sector (and in turn the economy) hinges upon the expansion of state-owned or statecontrolled power companies whose managers are keen to advance their political careers through enlarging the size of the assets under their control. The dominance of state ownership is also conducive to achieving other development/political objectives, in that it is easier for the government to promote the development of particular industries through the setting of preferential electricity prices, and to maintain social stability by keeping residential electricity prices low, if power companies are state-owned. The objectives of central and local governments are partly synergistic and partly conflictive. On the one hand, the pursuit of the central government's development goals depends, to a great extent, on the development of individual provinces. Appraising local governments according to economic growth may have strengthened the functional synergy between the development goals pursued by governments at different levels. On the other hand, local-oriented policies adopted by individual provinces may have negative externalities (including pollution) on other provinces and on the economy as a whole, which is where national and local goals are functionally conflictive. The central government tends to be more tolerant towards local policies that conflict with the centre's goals when the need for increased electricity supply and/or the promotion of economic growth becomes more pressing.

The goal of tackling pollution stands in considerable conflict with the sector's economic policy, given the abundance of coal in China and the irreplaceable role of coal-fired plants in serving peak loads. In turn, there is a lack of functional synergy between environmental objectives and the goal of supplying adequate electricity for economic growth. Despite drawing the increasing attention of the 
central government, environmental issues are not considered as ultimately vital for political legitimacy and stability, and therefore have received less political commitment than the task of ensuring adequate power supply. Local governments demonstrate even less commitment to environmental issues, which is unsurprising given the overriding economic criterion used to appraise local officials and substantial conflictive overlap between environmental objectives and local priorities.

Environmental considerations have become subordinate to the economic and development goals in policymaking and enforcement. The prioritizing of objectives and the nature of functional overlap between them explain the allocation of policy responsibilities among governing bodies and their position in the power structure. Given the importance of sectoral economic policy/regulation to the development and political goals, the NDRC - the key bureaucratic arm of the government - has maintained control over pricing and investment approval. It has been dominant in the competition among governing agencies and has overriding power over the MEP on issues where economic concerns conflict with environmental considerations. It's no surprise that the SERC was folded into the NEA and made subordinate to the NDRC. No fundamental change can be expected from this move if relations between various objectives and the political commitment to tackling pollution remain unchanged. When it comes to central-local government relations, the delegation of authority appears to prevail because of cyclic power shortages.

Under such a governance structure and process, the regulation and administration of electricity have been politicized. Regulatory policies/instruments have been designed and implemented primarily to expand generation capacity on the supply side, and to facilitate industrial development and maintain social stability on the demand side. Measures designed to preserve state ownership have been favoured for the purpose of control and to ease the advance of government objectives, central and/or local. As a result, the incentives from such policies/instruments are not (or are not intended to be) conducive to overcoming the economic barriers to the deployment of supply- and demand-side solutions.

\section{Pollution-control Measures in China}

In view of the above analysis, this section examines supply- and demand-side measures adopted in China. A full evaluation of their effectiveness warrants separate research and is beyond the scope of this paper. The aim of this section is to shed light on the challenges faced in the adoption of supply- and demand-side measures, drawing upon, where necessary, evidence reported in existing literature.

\section{Supply-side measures}

Major measures to reduce pollution from coal-based electricity generation include the so-called "big-up/small-down" scheme and a mandate to retrofit generating 
units with flue gas desulfurization (FGD) equipment. Commitment has been made to develop renewables to reduce coal's dominance in power generation.

The "big-up/small-down" scheme was introduced in 2007. Its primary aims are to phase out small and/or old generating units and to ensure that all newly installed units be at least 600MW. The NDRC introduced an initiative that lowered feed-in tariffs for small units as an economic incentive to support the scheme. It was reported that 553 units totalling $14.4 \mathrm{GW}$ capacity were shut down in $2007 .{ }^{87}$ Interestingly but unsurprisingly, most of the closed units were owned by the Big Five and almost all of the orders for new supercritical units were also placed by them. ${ }^{88}$ With access to finance usually unavailable to nonnational firms, the Big Five were able to afford the upfront investment needed to install new, large-scale units with advanced power cycles. In fact, they had a strong incentive to replace small units with larger ones under the cost-plus pricing regime and the current dispatch arrangement in which operating hours are allocated according to the size of installed capacity. However, there are reports that, once increased operating hours and relatively higher prices are secured in their power purchase agreements, many power stations have chosen to run the new units less often than the remaining older ones which incur low or no capital costs. ${ }^{89}$ They face no penalty for such a practice because of the problems with enforcing emission charges.

Enforcement of the scheme has been less encouraging at the local level, where the majority of small coal-fired units are concentrated. ${ }^{90}$ The aforementioned incentives are less relevant to locally based generators because their main concern is upfront investment. Even the incentivizing effects of lowering tariffs for small units is much diluted because of the role local governments play in setting final on-grid prices. As many local state-owned power plants are constructed with local government finance either through the banking system and/or through fiscal allocations, closing them would generate a significant strain on provincial banks and leave thousands of people unemployed..$^{91}$

In order to reduce $\mathrm{SO}_{2}$ emissions, in 2003 the MEP decreed that all new, expanded or retrofitted coal-fired units should install FGD equipment, and introduced pollution charges on $\mathrm{SO}_{2}$ emissions. ${ }^{92}$ The conflict of interests and lack of cooperation among the NDRC, SERC and MEP meant that the MEP directive and levies were not well enforced. ${ }^{93}$ In 2005, the NDRC introduced a feed-in tariff adder for generators with FGD-equipped units. Partly owing to this initiative and partly to the falling costs of domestic-manufactured FGD components,

87 http://www.serc.gov.cn/jgyj/ztbg/200804/t200804158883.htm

88 Ibid.

$89 \mathrm{Gao}$ and $\mathrm{Li} 2010$.

90 Kahrl et al. 2011.

91 Williams and Kahrl 2008.

92 Given the current limited feasibility in switching to low sulfur coal in the country, fitting abatement equipment has been the main approach to reducing $\mathrm{SO}_{2}$ emissions.

93 Chang and Wang 2010. 
progress has been recorded and, by the end of 2010, FGD-equipped units accounted for more than three-quarters of all thermal-based capacity. ${ }^{94}$ It should be noted that the tariff adder is granted to stations with FGD-equipped units rather than electricity generated from such units. It has been widely reported that many plants do not use the equipment for power generation because of high operating costs. ${ }^{95}$ The tariff adder may have encouraged installation but, given the problems with enforcing $\mathrm{SO}_{2}$ emissions charges, power producers have no incentive to switch on the scrubbers.

Quantity- and price-based schemes have been introduced to promote the development of renewable energy. A renewable electricity standard (RES) has been implemented whereby all generators with $5 \mathrm{GW}$ or more capacity must generate at least 8 per cent of their capacity from non-hydro renewables by $2020 .{ }^{96}$ Power purchasing agreements are used to oblige grid companies to grant grid connection and access to renewable plants and purchase all electricity generated.

A bidding-based concession scheme is used for large renewable projects. ${ }^{97}$ In order to meet the requirement of the RES and access the financial support for capacity installation usually attached to such projects, national state-owned generating companies bid aggressively and undercut their rivals with low bid prices, resulting in tariffs (the winning prices) too low to make the projects economically viable. ${ }^{98}$ All other projects are approved through the normal process, with tariffs set according to the FIT Scheme.

The RES, tendering system and FIT scheme are all biased towards encouraging capacity installation. This is in line with the electricity policy's overriding principle of expanding generation capacity. The incentives for generating electricity from installed capacity are weak, given the problems with enforcing emission charges and the insufficient price premiums for internalizing externalities. The refusal of grid companies to respect their connection and purchase agreement obligations stands as another major obstacle for renewable energy developers. The lack of economic incentives, accompanied by the weak authority of the SERC, has led to a poor enforcement of power purchasing agreements. A general observation is that rapid growth in installed capacity has not been matched by a corresponding growth in power generation and dispatch from renewable sources. ${ }^{99}$ It is estimated that around 30 per cent of installed capacity has been dormant and the other 70 per cent operates far below its nameplate capacity. ${ }^{100}$

94 IEA 2012.

$95 \mathrm{Li}, \mathrm{Ji}$, and Jiu Fu. 2008. "Thermal plants encouraged to increase desulfurization efforts," The China Daily, 19 January, 6.

96 National Development and Reform Commission 2007.

97 Projects granted through the scheme account for only a small portion of installed capacity. For instance, installed wind capacity through the scheme constituted $13 \%$ of all newly installed capacity in 2008 . See Garcia 2013.

98 Ibid.

99 Williams and Kahrl 2008; Garcia 2013.

100 Ibid. 


\section{Demand-side measures}

Demand-side solutions have received less attention. Industries are the largest consumers of electricity. In an attempt to control industrial electricity consumption, the central government has recently introduced price discrimination against selected energy-hungry industries. However, the intervention of local governments in setting local end-user rates has made enforcement difficult in provinces where the targeted industries are their economic lifeline. ${ }^{101}$ Some of the provinces have continued to issue preferential tariffs to enterprises in black-listed industries in order to promote local industrial development. ${ }^{102}$

Not much has been done to contain electricity demand by residential and commercial users despite the fact that their electricity consumption has grown rapidly over the last two decades. An increasing challenge relates to the potential high environmental cost of the resulting flattened system load factors and increased peak demand, which has to be met by keeping reserve coal-fired generating units running because China lacks gas-run peak plants. ${ }^{103}$

DSM measures are used sporadically in some provinces, mainly as a load management tool to deal with power shortages. Challenges for their systematic use as a solution to contain energy consumption come from the low prices for major end-user groups and the lack of incentive for grid companies to invest in DSM programmes under the current price regulation.

\section{Conclusions}

Applying an analytical framework which takes into account the literature on supply- and demand-side solutions, regulatory governance and EPI, this paper relates the regulatory framework to the environmental dimension of sustainable development in China's electricity industry. It finds that, in this economically and politically important sector, environmental considerations have become subordinate to the economic and development goals that are deemed crucial for political legitimacy. Regulatory policies/instruments have been intended to incentivize the expansion of generation capacity, facilitate industrial development, and help maintain social stability. However, they are not conducive to levelling the playing field for power plants using different technologies and to encouraging energy saving and energy efficiency by end users, and thereby give rise to challenges for the deployment of supply- and demand-side solutions.

It should be noted that China's development goals are diverse and that emphasis has shifted over time, from an overarching focus on growth targets in the 1990s to, in the current century, the pursuit of a broad development concept in which social and environmental parameters are included. ${ }^{104}$ This gives a 
glimpse of hope: environmental considerations are moving up the central government's agenda, and increasing political commitment may follow. In fact, rising public anger towards pollution in recent years has become one of the top spurs for social unrest in China. ${ }^{105}$ Environmental problems have become a growing, although not yet the most serious, threat to political legitimacy. This will increase synergetic overlap between environmental and development/political objectives, and in turn change the position of environmental considerations in relation to other concerns in the policy process. Given the important role of local governments in making local polices and enforcing national ones, it may prove crucial to integrate explicit environmental targets in the performance evaluations of local officials in order to align local priorities with the centre's environmental objectives.

\begin{abstract}
摘要：解决电力行业的污染问题需要使用供给与需求双方面的措施。但是, 这些措施的成功使用面临许多障碍。本文将注意力放在中国的电力行业, 把 该行业的监管体制与其在解决污染问题中所遇到的挑战和困难联系起来。 分析中使用的理论框架取材于监管治理, 供需方减排措施, 及环境政策一体 化方面的文献。分析结果表明，在中国电力工业的政策制定与执行的过程 中, 经济和发展目标是第一位, 而环境方面的考量处于从属地位。目前的监 管体制恰恰就是服务于这样一个决策定位。因此, 在这样的监管体制下所制 定和采取的监管政策与手段不利于清除减排措施所面临的障碍。
\end{abstract}

关键词: 中国; 电力行业; 环境问题; 监管体制; 环境政策一体化

\title{
References
}

Andrews-Speed, Philip. 2010. "The institutions of energy governance in China." Institut Français des Relations Internationales, http://www.ifri.org/en/publications/enotes/notes-de-lifri/institutions-energygovernance-china. Accessed 24 April 2015.

Andrews-Speed, Philip. 2012. The Governance of Energy in China: Transition to a Low-Carbon Economy. New York: Palgrave Macmillan.

Bonbright, James. 1961. Principles of Public Utility Rates. New York: Columbia University Press.

Chang, Yen-Chiang, and Nannan Wang. 2010. "Environmental regulations and emissions trading in China." Energy Policy 38, 3356-64.

Chen, Ling. 2010. "Playing the market reform card: the changing patterns of political struggle in China's electric power sector." The China Journal 64, 69-95.

Cheng, Tun-Jen, and Chung-min Tsai. 2009. "Powering rent seeking in the electricity industry." In Tak-Wing Ngo and Yongping Wu (eds.), Rent Seeking in China. London: Routledge, 117-144.

Collier, Ute. 1997. Energy and Environment in the European Union: The Challenge of Integration. Aldershot: Avebury Studies in Green Research.

Gao, Ciwei, and Li Yang. 2010. "Evolution of China's power dispatch principle and the new energy saving power dispatch policy." Energy Policy 38, 7346-57.

105 Shen, Feifei. 2013. "China air pollution triple WHO recommended levels in first half," Bloomberg News, 31 July. 
Garcia, Clara. 2011. "Grid-connected renewable energy in China: policies and institutions under gradualism, developmentalism, and socialism." Energy Policy 39, 8046-50.

Garcia, Clara. 2013. "Policies and institutions for grid-connected renewable energy: 'best practice' and the case of China." Governance 26(1), 119-146.

Global World Energy Council. 2005. "Wind force 12: a blueprint to achieve 12\% of the world's electricity from wind power by 2020," http://www.greenpeace.de/sites/www.greenpeace.de/files/ greenpeace_studie_windforce_12_1.pdf. Accessed 25 March 2015.

Green, Richard. 2008. "Carbon tax and carbon permits: the impact on generators' risks." The Energy Journal 29(3), 67-90.

Hemphill, Ross, Mark Meitzen and Philip Schoech. 2003. "Incentive regulation in network industries: experience and prospects in the US telecommunications, electricity, and natural gas industries." Review of Network Economics 2, 316-337.

Hood, Christopher, Oliver James, George Jones, Colin Scott and Tony Travers. 1999. Regulation inside Government: Waste-Watchers, Quality Police, and Sleaze-Busters. Oxford: Oxford University Press.

Hsueh, Roselyn. 2011. China's Regulatory State: A New Strategy for Globalization. Ithaca: Cornell University Press.

IEA (International Energy Agency). 1999. "Retrofit of power stations for green house gas abatement: case studies." IEA Greenhouse Gas Programme, Report No. Ph3/18.

IEA. 2006. China's Power Sector Reforms: Where to Next? Paris: IEA.

IEA. 2007. World Energy Outlook. Paris: IEA.

IEA. 2008. Deploying Renewables: Principles for Effective Policies. Paris: IEA.

IEA. 2012. "Non-greenhouse gas emission from coal-fired power plants in China," IEA Clean Coal Centre Profiles 12(4), http://www.iea-coal.org.uk/documents/82991/8493/Non-greenhouse-gasemissions-from-coal-fired-power-plants-in-China,-CCC/196.

Jordan, Andrew, and Andrea Lenschow (eds.). 2008. Innovation in Environmental Policy? Integrating the Environment for Sustainability. Cheltenham: Edward Elgar.

Kahrl, Fredrich, Jim Williams, Ding Jianhua and Hu Junfeng. 2011. "Challenges to China's transition to a low carbon electricity system." Energy Policy 39, 4032-41.

Kahrl, Fredrich, Jim Williams and Hu Junfeng. 2013. "The political economy of electricity dispatch reform in China." Energy Policy 53, 361-69.

Knudsen, Jørgen. 2010. "Integration of environmental concerns in a trans-Atlantic perspective: the case of renewable electricity." Review of Policy Research 27(2), 127-146.

Lafferty, William, and Eivind Hovden. 2003. "Environmental policy integration: towards an analytical framework." Environmental Politics 12(3), 1-22.

Lema, Adrian, and Kristian Ruby. 2007. "Between fragmented authoritarianism and policy coordination: creating a Chinese market for wind energy." Energy Policy 35(7), 3879-90.

Levy, Brian, and Pablo Spiller. 1994. "The institutional foundation of regulatory commitment: a comparative analysis of telecommunications regulation." Journal of Law, Economics and Organization 10(2), 201-246.

Liao, Cuiping, Eberhard Jochem, Yi Zhang and Nida Farid. 2010. "Wind power development and policies in China." Renewable Energy 35, 1879-86.

Lieberthal, Kenneth, and Michel Oksenberg. 1988. Policy Making in China: Leaders, Structures, and Processes. Princeton: Princeton University Press.

Lin, Kun-Chin, and Mika Purra. 2010. "Transforming China's industrial sectors: institutional change and regulation of the power sector in the reform era." Working Paper No. SPP10-12, Lee Kuan Yew School of Public Policy, National University of Singapore.

Littlechild, Stephen. 1983. Regulation of British Telecommunications' Profitability: Report to the Secretary of State. London: Department of Industry.

Ma, Jinlong. 2011. "On-grid electricity tariffs in China: development, reform, and prospects." Energy Journal 39, 2633-45. 
Maegli, Martin, and Christian Jaag. 2009. "Regulatory governance costs in network industries: implications for postal regulation.” MPRA Working Paper No. 15309, http://mpra.ub.uni-muenchen.de/ 15309/1/MPRA_paper_15309.pdf.

National Development and Reform Commission. 2007. Medium- and Long-Term Plan for Renewable Energy Development. Beijing: NDRC.

Peterson, Thomas, and Adam Rose. 2006. "Reducing conflicts between climate policy and energy policy in the US: the important role of the States." Energy Policy 34(5), 619-631.

Qiu, Xin, and Honglin Li. 2012. "Energy regulation and legislation in China." Environmental Law Reporter 42, 10678-693.

Rosen, Daniel, and Trevor Houser. 2007. "China energy: a guide for the perplexed." Washington, DC: Peterson Institute for International Economics.

Schout, Adriaan, and Andrew Jordan. 2005. "Coordinated European governance: self organizing or centrally steered." Public Administration 83(1), 201-220.

Spiller, Pablo, and Mariano Tommasi. 2005. "The institutions of regulation: an application to public utilities." In Claude Menard and Mary Shirley (eds.), Handbook of New Institutional Economics. Berlin: Springer, 515-543.

State Electricity Regulatory Council. 2011. Electricity Regulatory Annual Report 2010. Beijing: State Electricity Regulatory Commission.

Sun, Xuegong, Liyan Guo and Zeng Zheng. 2012. "Market entry barriers for FDI and private investors: lessons from China's electricity market.” ERIA Discussion Paper Series, ERIS-DP-2012-17. In Yanru Wu, Xunpeng Shi and Fukunari Kimura (eds.), Energy Market Integration in East Asia: Theories, Electricity Sector and Subsidies. Jakarta: ERIA, 83-102.

Williams, James, and Fredrich Kahrl. 2008. "Electricity reform and sustainable development in China." Environmental Research Letters 3(4), http://www.iop.org/EJ/article/1748-9326/3/4/ 044009/erl8_4_044009.html.

Wirtshafter, Robert. 1990. "Decentralization of China's electricity sector: is small beautiful?" World Development 18(4), 505-512.

World Bank. 2008. Financing Energy Efficiency: Lessons from Brazil, China, India, and Beyond . Washington, DC: World Bank.

$\mathrm{Xu}$, Chenggang 2011. "The fundamental institutions of China's reforms and development." Journal of Economic Literature 49(4), 1076-1151.

Yu, Yongzhen. 2012. "How to fit demand side management (DSM) into current Chinese electricity system reform?" Energy Economics 34, 549-557.

Zhang, Chi, and Thomas Heller. 2004. "Reform of the Chinese electric power market: economics and institutions." Stanford Program on Energy and Sustainable Development Working Paper No. 4, Stanford University.

Zhang, Yanhua, and Yongjun Chen. 2011. "Vertical relationship in China's electricity industry: the quest for competition?" Utilities Policy 19, 142-151.

Zhang, Zhe, and Si Xi. 2010. "Environmental tax delayed," Economic Observer On-Line, 29 March, http://www.eeo.com.cn/ens/Politics/2010/03/29/166354.shtml. Accessed 5 April 2012.

\section{Appendix}

Interviews were conducted in late 2010 and early 2011. Two officials from the NDRC, one from the SERC, and one from the EPM were interviewed to collect data on the cooperation and conflicts between those agencies, and between the agencies at the central level and their local branches. Four researchers from the Development Research Center of the State Council and the North China Electric Power University, who had conducted extensive research on China's electricity sector, were interviewed to supplement the data collected from the first 
498 The China Quarterly, 222, June 2015, pp. 475-498

group of interviewees, particularly with regard to the central-local government conflicts that the interviewed officials were reluctant to comment on. The analysis only uses the views that are shared by interviewees, and/or are consistent with the data collected from second-hand sources. 